\title{
REKAYASA MUTU TANAH PASIR PANTAI MELALUI APLIKASI BAHAN ORGANIK TERHADAP PERTUMBUHAN DAN PRODUKSI TANAMAN SAWI (Brassica juncea $\mathbf{L}$.)
}

\author{
Hijria*1), Eka Febrianti' $^{1)}$, Arsy Aysyah Anas' ${ }^{2)}$, La Ode Rustam ${ }^{2)}$, Muhammad \\ Botek $^{3)}$, Mirza Arsiaty Arsyad ${ }^{1)}$, dan La Ode Arfan Dedu ${ }^{4)}$ \\ ${ }^{1)}$ Jurusan Agroteknologi, Fakultas Pertanian Universitas Halu Oleo, Kendari \\ 2) Jurusan Ilmu Tanah, Fakultas Pertanian Universitas Halu Oleo, Kendari \\ ${ }^{3)}$ Jurusan Proteksi Tanaman, Fakultas Pertanian Universitas Halu Oleo, Kendari \\ 4) Jurusan Agribisnis, Fakultas Pertanian Universitas Halu Oleo, Kendari \\ *)e-mail : hijria1987@gmail.com
}

\begin{abstract}
Ringkasan
Salah satu lahan marjinal yang memiliki polibagensi tinggi untuk dikembangkan di Indonesia adalah lahan pantai. Sulawesi Tenggara memiliki panjang garis pantai sebesar $1.740 \mathrm{~km}$, namun masyarakat belum memanfaatkan lahan pasir pantai tersebut secara optimal, terutama untuk kegiatan pertanian. Tanaman yang berpolibagensi untuk dikembangkan di lahan pesisir adalah tanaman sawi mengingat permintaan yang terus meningkat dari tahun ke tahun. Secara nasional kemampuan produksi tanaman sawi Indonesia 8-10 ton $\mathrm{ha}^{-1}$. Di Sulawesi Tenggara produksi sawi rata-rata hanya 3,84 ton ha ${ }^{-1}$ dengan luas panen 165 ha. Penelitian ini bertujuan mengetahui pengaruh rekayasa mutu tanah pasir pantai melalui aplikasi bahan organik terhadap pertumbuhan dan produksi tanaman sawi. Penelitian menggunakan Rancangan Acak Lengkap dengan 4 perlakuan dengan 5 ulangan. Perlakuan yaitu tanpa pemberian pupuk organik, pupuk kompos kotoran sapi, pupuk organik Gaksi, dan kombinasi pupuk organik. Hasil penelitian menunjukkan bahwa kombinasi pupuk organik kompos kotoran sapi dan pupuk organik Gaksi terbaik pada perlakuan $100 \mathrm{~g}$ pupuk kompos kotoran sapi dengan $10 \mathrm{~g}$ pupuk organik Gaksi memberikan hasil terbaik terhadap pertumbuhan dan produksi tanaman sawi pada tanah pasir pantai.
\end{abstract}

Kata kunci : sawi, pupuk organik, pasir pantai 


\title{
QUALITY ENGINEERING OF SAND BEACH ON THE GROWTH AND PRODUCTION OF Brassica juncea L. BY APPLICATION OF ORGANIC COMPOUNDS
}

\begin{abstract}
A marginal land having high polybagency that can be developed in Indonesia is the coastal area. Southeast Sulawesi has large zone of coastline $(1,740 \mathrm{~km})$, yet the community has not utilized the coastal sand areas optimally, particularly for agricultural sector. A study has previously reported that sand beaches can be processed using horticulture and crop farming techniques. In this study, we investigated (1) whether sand beach can be employed as planting medium for Brassica juncea L., and (2) the effect of quality engineering on sand beach using organic compounds for increasing growth and production of B. juncea. Here, a Complete Randomized Design using four treatments was replicated five times. Thus, a total of 20 experimental units (polybags) were used in the analysis. The treatments were without organic fertilizer, cow manure compost fertilizer, Gaksi organic fertilizer, and combination of organic fertilizer. A combination of $100 \mathrm{~g}$ cow manure compost fertilizer and $10 \mathrm{~g}$ Gaksi organic fertilizer presented the highest growth and production of $B$. juncea in sand beach.
\end{abstract}

Keywords: Brassica juncea L., organic fertilizer, sand beach

\section{PENDAHULUAN}

Lahan pasir pantai merupakan lahan yang bermasalah dan mempunyai faktor pembatas tinggi untuk tanaman. Pemanfaatan teknologi di lahan kawasan pesisir diantaranya berupa teknologi perbaikan sifat fisik, kimiawi dan organisme tanah agar interaksi tanah-airtanaman dapat terwujud dengan baik. Wujud teknologi lain adalah pemberian pupuk organik, karena di lahan kawasan pantai yang perlu mendapatkan perhatian adalah tersedianya cukup unsur hara, cukup energi matahari dan energi angin. Hal ini bila tidak mendapatkan perhatian yang cukup dapat merugikan proses produksi biomas. Istiyanti, dkk. (2015) menyatakan bahwa tujuan perbaikan ini adalah agar tanah pasiran dapat terbentuk agregat, tidak lepas-lepas, mampu menahan air baik yang hilang berupa perlokasi atau evaporasi, mampu menyediakan unsur hara makro dan mikro bagi tanaman dan terwujudnya kekayaan mikro tanah yang dapat membantu kesuburan kimiawi dan fisika tanah.

Salah satu tanaman yang berpolibagensi untuk dikembangkan di lahan pesisir adalah tanaman sawi mengingat permintaan yang terus meningkat dari tahun ke tahun. Berdasarkan data statistik pertanian secara nasional kemampuan produksi tanaman sawi Indonesia 8-10 ton ha ${ }^{-1}$. Produksi sawi di Kecamatan Kendari Sulawesi Tenggara rata-rata 28 kwintal dengan luas panen 8 Ha. Budidaya tanaman sawi di Sulawesi Tenggara tahun 2019 diusahakan hanya di lahan tegalan/kebun yaitu sekitar 102 ha (0.07\%) (BPS Kecamatan Kendari, 2019).

Pupuk organik merupakan bahan pembenah tanah yang paling baik dibanding bahan pembenah lainnya, pemanfaatannya selain menciptakan sistem pertanian yang ramah lingkungan juga dapat mengurangi ketergantungan petani terhadap pupuk kimia. Pupuk organik memperbaiki struktur tanah, membantu penyerapan hara, mempertahankan suhu tanah, meningkatkan daya sangga tanah terhadap perubahan $\mathrm{pH}$, meningkatkan kapasitas tukar kation, menurunkan viksasi $\mathrm{P}$ dan sebagai reservoir unsur hara sekunder dan unsur mikro, serta sumber energi bagi mikroorganisme tanah yang berperan penting dalam proses 
dekomposisi dan pelepasan unsur hara dalam ekosistem tanah (Sanchez, 2008; Hadisuwito, 2012).

Salah satu pupuk organik yaitu pupuk kompos kotoran sapi yang memiliki kandungan $\mathrm{N}(0,7-1,3 \%), \mathrm{P} 2 \mathrm{O} 5(1,5-2,0 \%), \mathrm{K} 2 \mathrm{O}(0,5-0,8 \%), \mathrm{C}$ organik $(10,0-11,0 \%), \mathrm{MgO}$ $(0,5-0,7 \%)$, dan $\mathrm{C} / \mathrm{N}$ ratio $(14,0-18,0 \%)$ (Kusuma, 2012). Menurut Notohadiprawiro (2006), bahwa untuk mengatasi persoalan tanah masam dan C-Organik rendah adalah dengan memanfaatkan bahan organik seperti pupuk kandang sapi yang berfungsi sebagai ligan. Hasil penelitian Eko (2011) didapatkan informasi bahwa kualitas pupuk kandang sapi yang diberikan pada tanaman jagung mengandung mikroorganisme yang dapat menfermentasikan bahan organik sehingga menghasilkan senyawa yang dapat diserap langsung oleh tanaman. Selain itu, pupuk pupuk organik Gaksi juga merupakan salah satu pupuk organik yang diperkaya dengan agens hayati indegenos Sulawesi Tenggara yang dibuat dari bahan-bahan organik/kotoran ternak sapi/kambing yang diperkaya dengan mikroorganisme antagonis patogen, pendekomposer, pemfiksasi $\mathrm{N}$, pelarut $\mathrm{P}$ dan penghasil hormon tumbuh (Sutariati dan Wahid, 2012). Sutariati dan Khaeruni (2013) mengemukakan bahwa akan mampu meningkatkan ketersediaan unsur hara yang dibutuhkan oleh tanaman,, merangsang pertumbuhan dan memperbaiki sistem perakaran tanaman sehingga akar mampu berperan optimal dalam penyerapan unsur hara, meningkatkan kuantitas dan kualitas produksi tanaman dan mutu benih yang dihasilkan serta mempercepat waktu panen. Penelitian ini bertujuan mengetahui pengaruh rekayasa mutu tanah pasir pantai dengan menggunkan bahan organik untuk meningkatkan pertumbuhan dan produksi tanaman sawi.

\section{METODE PENELITIAN}

\section{Waktu dan Tempat}

Penelitian dilaksanakan pada bulan Agustus sampai Oktober 2019, di Kelurahan Padaleu, Kecamatan Kambu, Kendari, Sulawesi Tenggara.

\section{Alat dan Bahan}

Alat yang digunakan yaitu skop, polibag, cangkul, parang, waring, mistar ukur, oven, timbangan analitik, selang air, gembor, kamera dan alat tulis menulis. Sedangkan bahan digunakan adalah pupuk kompos kotoran sapi, pupuk organik Gaksi, pasir pantai, dan benih sawi hijau.

\section{Metode Penelitian}

Penelitian menggunakan Rancangan Acak Lengkap (RAL) terdiri atas 4 perlakuan yaitu tanpa pupuk organik $\left(\mathrm{H}_{0}\right)$, kompos kotoran sapi $100 \mathrm{~g} /$ polybag $\left(\mathrm{H}_{1}\right)$, pupuk organik Gaksi $10 \mathrm{~g} /$ polybag $\left(\mathrm{H}_{2}\right)$, dan kombinasi pupuk organik (kompos kotoran sapi 100 $\mathrm{g} /$ polybag + pupuk organik Gaksi $10 \mathrm{~g} /$ polybag) $\left(\mathrm{H}_{3}\right)$.

Pupuk rekomendasi setiap bahan organik kompos kotoran sapi 20 ton ha ${ }^{-1}$ (50 g/polybag) dan pupuk organik Gaksi 2 ton $\mathrm{ha}^{-1}$ (5 g/polybag). Setiap perlakuan pupuk organik ditingkatkan 2 kali dari jumlah pupuk rekomendasi, sehingga menjadi pupuk kompos kotoran sapi 100 g/polybag dan pupuk organik Gaksi 10 g/polybag. Perlakuan diulang sebanyak 5 kali sehingga terdapat 20 unit percobaan.

\section{Persiapan Media Tanam, Penanaman dan Pemeliharaan}

Polybag ukuran $31 \mathrm{~cm}$ x $30 \mathrm{~cm}$ sebanyak 20 polybag di isi media tanam dengan volume isi $5 \mathrm{~kg}$ tiap polybag yaitu tanah pasir pantai yang sudah dibersihkan dari kotoran seperti plastik, lamun, dan sampah lainnya. Pengaplikasian pemberian pupuk kompos kotoran sapi dan pupuk organik Gaksi bersamaan dengan pasir pantai yang akan dimasukkan ke dalam polybag. Pemberian pupuk dan pasir ini dilakukan berdasarkan 
perbandingan yang telah ditentukan. Sedangkan Pembibitan tanaman sawi dilakukan dengan cara setiap tray, diisi dengan 1 biji benih sawi. Pembibitan berlangsung selama 10 hari. Setelah 10 HST, dilakukan pemindahan bibit sawi pada polybag dengan ketentuan dipilih sawi dengan pertumbuhan dan tinggi yang seragam. Selain itu, diberi label pada masing-masing polybag berdasarkan perlakuan yang diberikan. Pemberian perlakuan dilakukan ketika biji telah berumur 10 HST. Perlakuan yang diberikan yaitu dosis pupuk kompos kotoran sapi dan pupuk organik Gaksi yang telah diberikan pada perlakuan awal yakni bersamaan dengan persiapan media. Pemeliharaan meliputi penyiraman pada pagi dan sore hari jika tidak hujan. Pengendalian hama dan penyakit dilakukan dengan cara menyemprotkan pestisida.

\section{Pemanenan}

Pemanenan dilakukan pada pagi hari, hal ini dilakukan agar tanaman sawi masih dalam keadaan segar. Panen dilakukan dengan cara mencabut seluruh tanaman. Hasil panen kemudian dicuci dengan air yang mengalir agar kotoran yang terdapat pada sawi ikut terbawa oleh air, setelah itu sawi dikering udarakan hingga air tidak menetes lagi untuk kemudian ditimbang beserta akarnya. Tanda sawi telah siap untuk dipanen adalah daun terbawahnya sudah mulai menyentuh tanah dan sudah mulai menguning.

\section{HASIL DAN PEMBAHASAN}

Pemberian pupuk organik pada pasir pantai pada umur 14 HST tidak memperlihatkan tinggi tanaman terbaik dan berbeda nyata dengan perlakuan pemberian berbagai macam pupuk organik pada pasir pantai pada umur 21 dan 28 HST (Tabel 1). Tinggi tanaman adalah refleksi dari suatu proses pertumbuhan tanaman sebagai akibat interaksi antara tanaman dengan faktor lingkungannya. Hasil penelitian ini sejalan dengan penelitian yang dilakukan oleh Suyitno dan Sudarson (2004) melaporkan bahwa tanaman sawi dapat tumbuh di pasir pantai dalam kondisi keadaan lingkungan yang keras menyebabkan bibit sawi mengalami stress untuk sementara waktu, terutama pada tahap awal pemindahan bibit dari tempat pembenihan ke tempat yang penanaman yang terbuka yang disebabkan oleh perubahan drastis kondisi lingkungan, bibit yang masih lemah, daun yang tipis dan lebar, suhu yang tinggi dan air yang terbatas.

Tabel 1. Rata-rata tinggi tanaman sawi pada umur 14, 21 dan 28 HST melalui aplikasi bahan organik pada media pasir pantai

\begin{tabular}{cccc}
\hline \multirow{2}{*}{ Perlakuan } & \multicolumn{3}{c}{ Rataan Pertumbuhan Tinggi Tanaman $(\mathrm{cm})$} \\
\cline { 2 - 4 } & $14 \mathrm{HST}$ & $21 \mathrm{HST}$ & $28 \mathrm{HST}$ \\
\hline H0 & 4.90 & $8.00^{\mathrm{abc}}$ & $8.18^{\mathrm{c}}$ \\
H1 & 5.98 & $9.90^{\mathrm{a}}$ & $11.22^{\mathrm{a}}$ \\
H2 & 5.22 & $7.30^{\mathrm{c}}$ & $8.48^{\mathrm{bc}}$ \\
H3 & 5.84 & $9.54^{\mathrm{ab}}$ & $10.68^{\mathrm{ab}}$ \\
\hline DMRT 0,05 & & $2=2.02$ & $2=2.07$ \\
& & $3=2.12$ & $3=2.18$ \\
& & $4=2.17$ & $4=2.23$ \\
\hline
\end{tabular}

Keterangan : Angka pada kolom yang sama diikuti oleh huruf berbeda menunjukkan beda nyata menurut uji DMRT pada taraf kepercayaan $95 \%$.

Prasetyo (2014) melaporkan bahwa pemberian bahan organik kotoran sapi pada tanaman cabai merah (Capsicum annum L.) di tanah berpasir dengan pemberian dosis pupuk organik yang berbeda akan mulai mengalami perbedaan tinggi tanaman setiap 
minggu, sehingga diduga adanya perbedaan kecepatan penyerapan unsur hara oleh tanaman. Pupuk kompos kotoran sapi memiliki kandungan air yang lebih tinggi dibandingkan dengan jenis perlakuan pupuk kandang lainnya yakni $85 \%$ bobot sehingga tingkat kelembapan akan semakin tinggi, dengan tingkat kelembapan yang tinggi proses dekomposisi akan semakin cepat dan unsur hara yang terkandung pada pupuk kandang tersebut akan tersedia bagi tanaman sehingga unsur hara dapat terserap dan meningkatkan pertumbuhan tanaman. Pemberian pupuk kompos kotoran sapi pada tanah Entisols mampu meningkatkan kapasitas tukar kation tanah dan suplai hara P, S dan N (Fikdalillah dkk., 2016). Menurut Perwitasari et al., (2012) bahwa penambahan pupuk yang lebih banyak juga mempengaruhi perkembangan akar sehingga nutrisi dapat diserap dengan optimal.

Tabel 2. Rata-rata jumlah daun tanaman sawi pada umur 14, 21 dan 28 HST melalui aplikasi bahan organik pada media pasir pantai

\begin{tabular}{cccc}
\hline \multirow{2}{*}{ Perlakuan } & \multicolumn{3}{c}{ Rataan Pertumbuhan jumlah daun (helai) } \\
\cline { 2 - 4 } & $14 \mathrm{HST}$ & $21 \mathrm{HST}$ & $28 \mathrm{HST}$ \\
\hline H0 & $2.80^{\mathrm{c}}$ & $3.20^{\mathrm{c}}$ & $4.20^{\mathrm{c}}$ \\
H1 & $4.20^{\mathrm{ab}}$ & $4.40^{\mathrm{ab}}$ & $5.20^{\mathrm{ab}}$ \\
H2 & $3.00^{\mathrm{b}}$ & $3.60^{\mathrm{abc}}$ & $4.60^{\mathrm{ab}}$ \\
H3 & $4.40^{\mathrm{a}}$ & $4.60^{\mathrm{a}}$ & $5.40^{\mathrm{a}}$ \\
\hline DMRT 0,05 & $2=0.99$ & $2=0.97$ & $2=0.82$ \\
& $3=1.04$ & $3=1.02$ & $3=0.86$ \\
& $4=1.07$ & $4=1.05$ & $4=0.88$
\end{tabular}

Keterangan : Angka pada kolom yang sama diikuti oleh huruf berbeda menunjukkan beda nyata menurut uji DMRT pada taraf kepercayaan $95 \%$.

Tabel 2. menunjukkan bahwa peningkatan takaran pupuk organik secara nyata meningkatkan jumlah daun tanaman sawi pada media pasir pantai. Hal ini diduga pemberian pupuk organik yang semakin tinggi (kombinasi unsur hara) yang diberikan, maka dapat dimanfaatkan untuk proses fisiologi tanaman tersebut seperti jumlah daun dan luas daun. Hasil penelitian ini sejalan dengan penelitian yang dilakukan oleh Yuwono (2015) melaporkan bahwa penggunan pupuk kompos kotoran sapi dapat menjadi alternatif penganti pupuk $\mathrm{N}$, P, dan $\mathrm{K}$ secara organik dalam sistem budidaya tanaman dan menjaga kesuburan tanah di lahan marginal.

Tabel 3. Rata-rata bobot segar tanaman sawi melalui aplikasi bahan organik pada media pasir pantai

\begin{tabular}{cc}
\hline Perlakuan & Rataan bobot segar sawi (g) \\
\hline H0 & $1.25^{\mathrm{c}}$ \\
H1 & $1.49^{\mathrm{b}}$ \\
H2 & $3.02^{\mathrm{ab}}$ \\
H3 & $4.34^{\mathrm{a}}$ \\
\hline DMRT 0,05 & $2=1.59$ \\
& $3=1.67$ \\
& $4=1.71$ \\
\hline
\end{tabular}

Keterangan : Angka pada kolom yang sama diikuti oleh huruf berbeda menunjukkan beda nyata menurut uji DMRT pada taraf kepercayaan $95 \%$. 
Peningkatan takaran pupuk organik secara nyata meningkatkan bobot segar tanaman sawi pada media pasir pantai (Tabel 3). Diduga bobot segar yang tinggi pada perlakuan ini disebabkan oleh jumlah daun dan tinggi tanam yang relatif tinggi. Dimana diketahui bahwa terdapat hubungan yang berbanding lurus antara jumlah daun dan tinggi tanaman. Semakin banyak daun makan berat basah tanaman juga semakin besar begitupula dengan tinggi tanaman, makin tinggi tanaman berat basah juga semakin tinggi (Mursalim et al, 2018). Hal ini sesuai dengan pendapat Pangribuan (2012), pada komoditas sayuran daun jumlah daun akan berpengaruh terhadap berat segar tajuk. Semakin banyak jumlah daun maka akan menunjukkan berat segar tajuk yang tinggi, berat basah tanaman juga semakin besar akan tetapi dalam penelitian ini antara jumlah daun dan tinggi tanaman tidak berbanding lurus.

Jamilah (2003) dalam Indriyani dkk. (2018) menyatakan bahwa semakin tinggi unsur hara yang diberikan dari bahan organik serta mengandung unsur hara nitrogen dapat merangsang pembentukan daun sehingga jaringan meristematik pada titik tumbuh batang semakin aktif dan semakin banyak ruas batang yang terbentuk sehingga semakin banyak daun yang dihasilkan, akibatnya jumlah daun, luas daun, bobot segar, dan bobot kering semakin meningkat. Hal tersebut sesuai dengan pernyataan Yani (2013) bahwa penambahan pupuk yang lebih banyak juga mempengaruhi perkembangan akar sehingga nutrisi dapat diserap dengan optimal. Nutrisi sangat mempengaruhi pembentukan daun, terutama unsur nitrogen (N). Menurut Afandi dkk., (2015) mengemukakan bahwa unsur N memiliki fungsi utama untuk perkembangan vegetatif tanaman seperti pembentukan daun. Daun sebagai organ penyusun tanaman berfungsi untuk menerima dan menyerap cahaya dan menjadi bagian tanaman yang berfungsi sebagai tempat berfotosintesis sehingga menjadi tempat produksi fotosintat untuk seluruh bagiantanaman.

Selain ketersediaan unsur $\mathrm{N}$ yang mencukupi, berat segar biomassa tanaman juga dipengaruhi oleh beberapa faktor eksternal dan faktor internal tanaman. Faktor eksternal seperti iklim (cahaya, suhu, air, panjang hari, angin dan gas), tanah (tekstur, struktur tanah, kandungan bahan organik, kapasitas pertukaran kation), dan biologis (gulma, serangga, organisme penyebab penyakit, macam-macam tipe herbivora, dan mikro organisme tanah). Sedangkan faktor internal yang mempengaruhi adalah ketahanan tanaman terhadap tekanan dari faktor eksternal, laju fotosintesis, respirasi, ketrsediaan klorofil, pembagian hasil asimilasi $\mathrm{N}$, kapasitas untuk menyimpan cadangan makanan, aktivitas enzim, pengaruh langsung dari gen tanaman itu sendiri, dan differensiasi (Rizky, 2010).

Tabel 4. Rata-rata bobot kering tanaman sawi melalui aplikasi bahan organik pada media pasir pantai

\begin{tabular}{cc}
\hline Perlakuan & Rataan bobot kering sawi $(\mathrm{g})$ \\
\hline H0 & $0.11^{\mathrm{b}}$ \\
H1 & $0.12^{\mathrm{b}}$ \\
H2 & $0.24^{\mathrm{b}}$ \\
H3 & $0.32^{\mathrm{a}}$ \\
\hline DMRT 0,05 & $2=0.12$ \\
& $3=0.13$ \\
& $4=0.13$ \\
\hline
\end{tabular}

Keterangan : Angka pada kolom yang sama diikuti oleh huruf berbeda menunjukkan beda nyata menurut uji DMRT pada taraf kepercayaan $95 \%$. 
Rata-rata berat kering (Tabel 4) tanaman sawi tertinggi dicapai oleh perlakuan pemberian kombinasi pupuk organik yaitu antara pupuk kompos kotoran sapi dan pupuk organik Gaksi (H3). Sejalan dengan penelitian Fikdalilla dkk. (2016) menyatakan bahwa naiknya nilai bobot kering tanaman mengikuti jumlah dosis pupuk kandang sapi yang ditambahkan. Hubungan antara dosis pupuk kandang sapi berarti menambah kadar COrganik pada tanah. Peningkatan bobot kering tanaman tersebut membuktikan bahwa pertumbuhan tanaman semakin baik dengan adanya pemberian bahan organik. Pemberian bahan organik pada tanah dapat memperbaiki aerasi dan draenase tanah, mempertahankan kandungan air dalam tanah, dan menurunkan bobot isi tanah sehingga konsistensi tanah lebih gembur yang memungkinkan akar tumbuh dan berkembang dengan baik. Prasetyo (2014) menyatakan bahwa semakin cepatnya unsur $\mathrm{N}$ dapat diserap oleh tanaman dalam suatu sumber pupuk organik maka akan mempengaruhi berat segar dan berat kering tanaman. Franklin et al., (2008) mengemukakan bahwa berat kering biomassa tanaman sangat dipengaruhi oleh proses pertumbuhan dan diferensiasi sel tanaman. Proses diferensiasi tanaman mempunyai tiga syarat yaitu hasil asimilasi yang tersedia dalam keadaan berlebihan untuk dapat dimanfaatkan pada kebanyakan kegiatan metabolik, temperatur yang menguntungkan, dan terdapat sistem enzim yang tepat untuk memperantarai proses diferensiasi. Apabila dari ketiga persyaratan tersebut dapat terpenuhi, maka akan terjadi penebalan dinding sel, deposit dari sebagian sel, pengerasan protoplasma.

\section{KESIMPULAN}

1. Penggunaan kombinasi pupuk organik pada media pasir pantai dapat meningkatkan pertumbuhan dan produksi tanaman sawi

2. Kombinasi perlakuan dosis pupuk organik $100 \mathrm{~g}$ dengan jenis pupuk organik Gaksi 10 g (H3) merupakan kombinasi perlakuan terbaik yang saling memberikan interaksi yang nyata terhadap variabel tinggi tanaman, jumlah daun, bobot segar tanaman dan bobot kering tanaman sawi pada media pasir pantai.

\section{DAFTAR PUSTAKA}

Afandi, NF, Siswanto B, dan Nuraini Y. 2015. Pengaruh Pemberian Berbagai Jenis Bahan Organik Tehadap Sifat Kimia TanahTerhadap Pertumbuhan dan Produksi Tanaman Ubi Jalar di Entisol Ngarakah Pawon, Kediri. Jurnal Tanah dan Sumberdaya Lahan. Vol. 2 No. 2. Hal. 237-244.

Ariyanto. Shodiq Eko. 2011. Perbaikan Kualitas Pupuk Kandang Sapid an Aplikasinya pada Tanaman Jagung Manis (Zea mays saccharata Sturt). Jurnal Sains dan Teknologi. Vol. 4, No.2.

Bondansari, S. dan Bambang, S.S. 2011. Pengaruh Zeloit dan Pupuk Kandang Tehadap Beberapa Sifat Fisik Tanah Ultisol dan Entisol Pada Pertanian Kedelai (Glycine max L. Merril.). Fakultas Pertanian Universitas Jendral Soedirman, Purwokerto.

BPS Kecamatan Kendari Dalam Angka 2019. BPS Sulawesi Tenggara Tahun 2019. Sulawesi Tenggara.

Fikdalillah, Muh. Basir dan Imam Wahyudi. 2016. Pengaruh Pemberian Pupuk Kandang Sapi Terhadap Serapan Fosfor dan Hasil Tanaman Sawi Puti (Brassica pekinensis) Pada Entisols Sider. e-J. Agrotekbis Vol. 4 No. 5. Hal. 491-499.

Franklin P.G., R. Brent P., Roger L.M. 2008. Fisiologi Tanaman Budidaya. Penerbit Universitas Indonesia (UI Press). Jakarta.

Hadisuwito.S., 2012. Membuat Pupuk Organik Cair. Agromedia Pustaka, Jakarta Selatan. 
Istiyanti E, Khasanah U, dan Anjarwati A., 2015. Pengembangan Usahatani Cabai Merah di Lahan Pasir Pantai Kecamatan Temon Kabupaten Kulonprogo. Vol.I No.1 Januari 2015. Program Studi Agribisnis Universitas Muhammadiyah Yogyakarta. Akses tanggal 21 Agustus 2019.

Jamilah, SP. MP. 2003. Pengaruh Pemberian Pupuk Kandang dan Kelengasan Terhadap Perubahan Bahan Organik dan Nitrogen Total Entisol. Universitas Sumatera Utara.http://repository.usu.ac.id/bitstream/123456789/1133/1/tanah-jamilah.pdf.

Diakses Pada 12 Agustus 2019.

Kusuma, M.E. 2012. Pengaruh beberapa jenis pupuk kandang terhadap kualitas Bokashi. Jurnal Hewani Tropika. Vol. 1 No. 2. Hal. 41-46.

Mirsalim I, Mysatami MK, Ali A. 2018. Pengaruh Penggunaan Pupuk Organik Mikroorganisme Lokal Media Nasi, Batang pisang, dan Ikan Tongkol Terhadap Pertumbuhan Tanaman Sawi (Brasicca juncea). Jurnal Biotek Vol. 6 No. 1.

Nurjannah, Ifatrul Yani. 2013. Pengaruh Beberapa Jenis Pupuk Kandang Terhadap Pertumbuhan dan Hasil Tanaman Cabai Merah Pada Tanah Gambut. http://webcache.googleusercontent.com/search?q=cache:GyNHA1wVad0J:jurnal. untan.ac.id/index.php/jspp/article/view/1185/1199+\&cd=1\&hl=en\&ct=clnk\&client=f irefox-a. Diakses Pada 13 Agustus 2019.

Notohadoprawiro, 2006. Pengelolaan Kesuburan Tanah dan Peningkatan Efisiensi Pemupukan. http://soilfaperta.ugm.ac.id/tj/1981/1984\%20.pdf. Diakses tanggal 10 Agustus 2019

Pangaribuan DH. 2012. Pengaruh Pupuk Organik Cair Terhadap Pertumbuhan dan Produksi Sayuran Kangkung, Bayam dan Caisim. Prosiding Seminar Nasional PERHORTI ISBN : 978-9779-25-1265-6

Perwitasari, B., M. Tripatmasari., dan C. Wasonowati. 2012. Pengaruh Media Tanam dan Nutrisi Terhadap Pertumbuhan Tanaman Pokchoi (Brasicca juncea L.) dengan sistem Hidroponik. Agrovigor. Vol. 1 hal. 14 - 25.

Prasetyo. 2014. Pemanfaatan Berbagai Sumber Pupuk Kandang sebagai Sumber N dalam Budidaya Cabai Merah (Capsicum annum L.) di Tanah Berpasir. Jakarta.

Rizky Bayo. D. 2010. http://catatanbayodongoran.blogspot. com/2010/10/perkecambahantujuan-untuk-mempelajari. html. Diakses Pada 11 Agustus 2019.

Sanchez, P.A., 2008. Properties and Management of Soil in the Tropic Soil Organic Matter. New York : John Wiley and Sons. 5 : 225-270

Sutariati GAK, Khaeruni A. 2013. Seed Biomatriconditioning Using Rhizobacteria for Growth Promotion and Increase the Yield of Sorghum (Sorghum bicolour (L.) Moench) on Marginal Soil. Agricultural Science Research Journal, 3(3):85-92.

Sutariati GAK, Wahid A. 2012. Karakter Fisiologis dan Kemangkusan Rizobakteri Indigenus Sulawesi Tenggara sebagai Pemacu Pertumbuhan Tanaman Cabai. Jurnal Hortikultura, 22(1): 57-64.

Yuwono M.W., 2015. Membangun Kesuburan Tanah Di Lahan Marginal. Jurnal Ilmu Tanah dan Lingkungan Vol. 9 No. 2 (2015) p: 137-141. Akses tanggal 23 Agustus 2019 